\title{
Delivery of Nerve Growth Factor to the Brain via the Olfactory Pathway
}

\author{
Xue-Qing Chen ${ }^{a,}$, John R. Fawcett ${ }^{b}$, Yueh- \\ Erh Rahman ${ }^{a}$, Thomas A. Ala ${ }^{b}$ and William \\ H. Frey II ${ }^{a, b}$ \\ ${ }^{a}$ Graduate Program in Pharmaceutics, \\ College of Pharmacy, University of \\ Minnesota, Minneapolis, MN 55455, USA \\ ${ }^{b}$ Alzheimer's Research Center, Health \\ Partners at Regions Hospital, St. Paul, MN \\ 55101, USA
}

\begin{abstract}
Purpose: To assess the potential of delivering nerve growth factor (NGF) to the brain along the olfactory neural pathway for the treatment of Alzheimer's disease. Methods: Recombinant human NGF (rhNGF) was given as nose drops to anesthetized rats. The rhNGF concentrations in the brain were determined by enzyme-linked immunosorbent assay (ELISA). Results: Following olfactory administration, rhNGF reached the brain within an hour, achieving a concentration of $3400 \mathrm{pM}$ in the olfactory bulb, 660$2200 \mathrm{pM}$ in other brain regions and, $240 \mathrm{pM}$ and 180 $\mathrm{pM}$ in the hippocampus and the amygdala, respectively. In contrast, little or no rhNGF was found in the brain following intravenous administration. Conclusions: A significant amount of rhNGF can be delivered to the brain via the olfactory pathway. The detection of rhNGF by ELISA indicates that rhNGF is delivered to the brain relatively intact. The rapid appearance of rhNGF in the brain suggests that it may be transported by an extraneuronal route into the brain via intercellular clefts in the olfactory epithelium. Further work to clarify the transport mechanism is underway. The olfactory pathway is a promising, non-invasive route for drug delivery to the brain, which has potential for the treatment of neurodegenerative diseases including Alzheimer's disease.
\end{abstract}

\footnotetext{
* Correspondence author. Tel.: +1 612 221-3019;

Fax:+1612 292-4040; E-mail: chen0189@maroon.tc.umn.edu.
}

Keywords: Nerve growth factor, olfactory, drug delivery, brain, Alzheimer's disease.

\author{
Abbreviations: \\ BDNF: brain-derived neurotrophic factor \\ ChAT: choline acetyltransferase \\ ELISA: enzyme-linked immunosorbent assay \\ NGF: nerve growth factor \\ hNGF: recombinant human NGF \\ NT-3: neurotrophin-3 \\ O.P.: olfactory pathway
}

\section{INTRODUCTION}

Alzheimer's disease (AD) is a progressive neurodegenerative disease of the brain. It affects about 4 million Americans with an annual cost for custodial care of more than 90 billion dollars. In addition to the presence of senile plaques and neurofibrillary tangles in the cerebral cortex, the most consistent pathologic finding in $\mathrm{AD}$ is the degeneration of specific cholinergic neuronal populations, resulting in a reduction in choline acetyltransferase (ChAT) activity (27). These cholinergic losses may contribute to clinical manifestations such as memory loss and cognitive decline (27).

Nerve growth factor (NGF), the best characterized neurotrophic factor, exhibits trophic effects primarily on cholinergic neurons in the basal forebrain of the central nervous system (CNS) (9). NGF is synthesized in the hippocampus and the neocortex and retrogradely transported to the cell bodies of basal forebrain cholinergic neurons following binding to NGF receptors $(26,29,33)$. NGF elevates ChAT activity both in vitro and in vivo $(11,18)$. It also prevents cholinergic cell loss in the basal forebrain following fimbria-fornix lesion in both 
rats and monkeys $(13,15)$. Further, it ameliorates learning impairment in aged animals (7). In recent years, NGF has received attention as a potential therapeutic agent for AD. Although it remains unknown whether NGF is directly involved in the pathogenesis of $\mathrm{AD}$, treatment with exogenous NGF may counteract cholinergic degeneration and improve memory and cognition, as has been demonstrated in animal studies.

The potential use of NGF for treating AD will require the delivery of NGF to affected brain regions. However, as a $26.5 \mathrm{kDa}$ protein dimer, NGF is unable to appreciably cross the bloodbrain barrier (BBB), making its delivery to the brain difficult. While delivery methods such as intracerebroventricular infusion and grafting of NGF-producing cells have been developed, the associated surgical risks and high cost may limit the use of these methods in humans (12). The development of a less-invasive, lower cost delivery method for NGF may therefore significantly improve the prospects of using NGF clinically. Delivery of NGF to the CNS via the olfactory pathway is a novel, non-invasive drug delivery strategy in which the BBB is bypassed. Although some evidence exists that substances may enter the brain via the nasal mucosa, little attention has been paid to the olfactory pathway as a possible route for delivering drugs, especially protein drugs, to the brain.

The existence of an anatomical connection between the brain and nasal cavity makes olfactory delivery of NGF possible. The olfactory receptor cells in the olfactory epithelium are bipolar sensory neurons and are the only cells in the brain in direct contact with both the CNS and the external environment. The dendrites of these neurons extend into the nasal cavity, whereas the axons collect into nerve bundles and project to the olfactory bulb (17). The olfactory bulb has a widespread connection with various brain regions including the horizontal diagonal band, locus ceruleus, raphe nucleus, entorhinal cortex and amygdala, all of which are affected in AD (17). In addition, physiologic studies have shown that the cerebrospinal fluid (CSF) drains from the subarachnoid space along olfactory neurons to the nasal submucosa and nasal lymphatic system $(3,10)$. This finding provides further evidence for a direct connection between the nose and the brain. A variety of substances, including metals $(5,8)$, dyes $(30)$, viruses $(21)$, peptides $(22,23)$, proteins $(1,2,28)$ and drugs $(4,24)$, have been reported to reach the brain from the nasal cavity, without having to cross the BBB.

Drug delivery via the olfactory pathway may be particularly beneficial for AD patients since the olfactory system is involved in the disease. A deficit in the sense of smell is often an early symptom in AD patients (19). Pathologic changes have been found in the olfactory mucosa and olfactory bulb as well as other brain regions interconnected with the olfactory bulb (31). It has been suggested that the disease may extend from the olfactory epithelium to the brain along the connecting fibers (31).

Previous work in our laboratory has found that a significant amount of radiolabeled murine NGF can be delivered to the brain via the olfactory pathway. We also found that about $80 \%$ of the radiolabel detected in the brain could be precipitated by trichloroacetic acid (6). In the present study, a sensitive two-site enzyme-linked immunosorbent assay (ELISA) was utilized to determine both endogenous NGF in the brain and the concentration of recombinant human NGF (rhNGF) delivered to various brain regions following olfactory pathway administration.

\section{MATERIALS AND METHODS}

\section{Materials}

Recombinant human NGF was generously provided by Genentech, Inc. (San Francisco, CA). Anti-NGF monoclonal antibody and AntiNGF conjugated with $\beta$-galactosidase (AntiNGF- $\beta$-galactosidase) were purchased from Boehringer Mannheim (Indianapolis, IN). Brainderived neurotrophic factor (BDNF) and neurotrophin-3 (NT-3) were obtained from Calbiochem (La Jolla, CA). The substrate Chlorophenol red- $\beta$-D-galactopyranoside was 
from Calbiochem-Novabiochem Co. (La Jolla, CA). Urethane was from Sigma (St. Louis, MO). The Nunc-immuno plates were purchased from Gibbco Scientific (Coon Rapids, MN). The Vmax kinetic microplate reader was obtained from Molecular Devices Co. (Palo Alto, CA). All other chemicals used to prepare the buffer solutions were of analytical reagent grade.

\section{Administration of NGF to Rats}

Male Sprague-Dawley rats (200-280 g) were anesthetized with an intraperitoneal injection of urethane $(1.7 \mathrm{~g} / \mathrm{kg})$. All surgical procedures were approved by the Animal Care and Use Committee at Regions Hospital (St. Paul, MN) and complied with the Principles of Laboratory Animal Care guidelines (NIH publication \#85-23, revised 1985).

Olfactory Pathway (O.P.) Administration. Recombinant human NGF (9.15 nmole) in a 40 $\mathrm{mM}$ potassium phosphate buffer, $\mathrm{pH} 7.0$, was used for O.P. administration. The anesthetized rats were placed on their backs, and $100 \mu 1$ rhNGF solution was given in nose drops $(\sim 6 \mu \mathrm{l})$ over $30 \mathrm{~min}$, alternating drops every two minutes between the left and right nares. During the administration, the mouth and the opposite naris were closed so the drops could be naturally inhaled.

Intravenous (I.V.) Administration. One femoral vein was cannulated for I.V. injection. Two different doses were used in this study. The high dose ( 9.15 nmole) was the same dose used in rats receiving O.P. administration of rhNGF, whereas the low dose (100 pmole) was determined previously in our laboratory to achieve approximately the same blood concentration of rhNGF as that obtained with O.P. administration of 9.15 nmoles rhNGF (6).

Controls. Control rats received phosphate buffer solution over the same time period by O.P. or I.V. administration. These rats were also used for the determination of endogenous NGF.

\section{Brain Dissection and CSF Collection}

After the $30 \mathrm{~min}$ O.P. administration or an equivalent time following I.V. injection, the aorta was cannulated and upper body perfusion was performed with $50 \mathrm{ml}$ saline in order to remove blood from the brain. Following perfusion, the brain was dissected, weighed, immediately frozen in liquid $\mathrm{N}_{2}$ and stored at $-70{ }^{\circ} \mathrm{C}$ until use. Dissected regions included the olfactory bulb, cerebellum, brain stem, and four approximately equal coronal brain sections labeled as B1, B2, $\mathrm{B} 3$ and B4. In addition, some interior regions of the brain such as the amygdala and the hippocampus were also dissected out. rhNGF concentrations in these brain regions were determined by ELISA. The olfactory epithelium was also dissected at $0,2,5$ and $20 \mathrm{hr}$ after O.P. administration, and the time course of rhNGF uptake was determined.

In some studies, CSF was collected after administration. An incision was made in the skin over the occipital bone and the first layer of the muscle was cut. CSF was obtained by cisternal puncture with a 23-gauge needle connected to polyethylene tubing. Collection was terminated as soon as any blood began to appear in the tubing (24).

\section{ELISA Assay}

The concentrations of rhNGF in brain tissue samples were determined using a previously described sandwich ELISA (Boehringer Mannheim) with minor modification. Briefly, the brain tissue was homogenized at a 1:5 (w/v) dilution in extraction buffer (100 mM Tris-HCl, $400 \mathrm{mM} \mathrm{NaCl}, 2 \%(\mathrm{w} / \mathrm{v})$ bovine serum albumin, $0.05 \%$ sodium azide, $1 \mathrm{mM}$ phenylmethylsulfonylfluoride (PMSF), $7 \mu \mathrm{g} / \mathrm{ml}$ aprotinin and 4 mM EDTA, $\mathrm{pH}$ 7.0). PMSF and aprotinin are protease inhibitors which were used to inhibit the enzymatic degradation of rhNGF during the assay. The homogenates from the samples and standards were frozen in liquid $\mathrm{N}_{2}$ and then thawed in room temperature water (three times) 
to release NGF from membrane receptors. Following centrifugation for $10 \mathrm{~min}$ at $16,000 \mathrm{~g}$, the supernatant fractions, 1:30 (w/v) dilution, were added to the plate coated with anti-NGF. After overnight incubation at room temperature and extensive rinsing with washing buffer (50 $\mathrm{mM}$ Tris- $\mathrm{HCl}, 200 \mathrm{mM} \mathrm{NaCl}, 10 \mathrm{mM} \mathrm{CaCl} 2$, $0.1 \%$ triton $\mathrm{X}-100(\mathrm{w} / \mathrm{v}), 0.1 \%$ sodium azide $(\mathrm{w} / \mathrm{v}), \mathrm{pH} 7.0)$, the anti-NGF- $\beta$-galactosidase was added. The optical density of the developed color was measured on a plate reader at $562 \mathrm{~nm}$ following addition of the substrate. The standard curve was obtained by adding known concentrations of $\mathrm{rhNGF}(0.0625-1 \mathrm{ng} / \mathrm{ml})$ to the brain tissue homogenate from a control rat and then assaying the resultant supernatant fractions.

In order to examine the specificity of our NGF ELISA, other members of the neurotrophin family such as brain-derived neurotrophic factor (BDNF) and neurotrophin-3 (NT-3) were also tested. BDNF and NT-3 are known to have sequence homology to NGF and similar affinity for p75 NGF receptors. BDNF and NT-3 were tested in the ELISA at concentrations ranging from $0.5 \mathrm{ng} / \mathrm{ml}$ to $500 \mathrm{ng} / \mathrm{ml}$.

\section{In Vitro Stability of rhNGF}

In vitro stability of rhNGF was investigated in the presence of brain tissue, CSF or olfactory epithelium. rhNGF was added to the brain tissue homogenate from a control rat at a final concentration of $0.5 \mathrm{ng} / \mathrm{ml}$ and incubated at $37^{\circ} \mathrm{C}$. Samples were collected at $0,10,20,30$, 45, 60, 90 and $120 \mathrm{~min}$. rhNGF was also added to the CSF and to a homogenate of the olfactory epithelium from control rats, and similar procedures were performed.

\section{Determination of Endogenous NGF in the Brain}

Brain tissues from control rats were used to determine the endogenous concentration of NGF in various brain regions. Specifically, a standard curve was prepared using the supernatant fraction of a given part of brain tissue. The optical density found in the absence of added rhNGF, which resulted from the endogenous NGF as well as the blank due to the non-specific binding, was then subtracted from all data points to generate a modified curve. The unknowns with the blank subtracted were then calculated using the modified standard curve in order to determine the endogenous level of NGF in this brain region.

\section{RESULTS}

\section{Validation of ELISA Assay}

A typical ELISA standard curve for rhNGF performed in the presence of the supernatant fraction of rat brain is shown in Fig. 1. The optical density found in the absence of added rhNGF has been subtracted from all data points. The detection limit of the assay is about $4 \mathrm{pM}$.

Recovery of rhNGF from Brain Tissue. Known amounts of rhNGF were added to control tissue homogenates at $0^{\circ} \mathrm{C}$. The recovery of rhNGF from the brain tissue was expressed as the amount of rhNGF detected in the tissue, taking the total rhNGF added as $100 \%$. We found that the recovery of added rhNGF from the brain tissue homogenates was about $35-50 \%$.

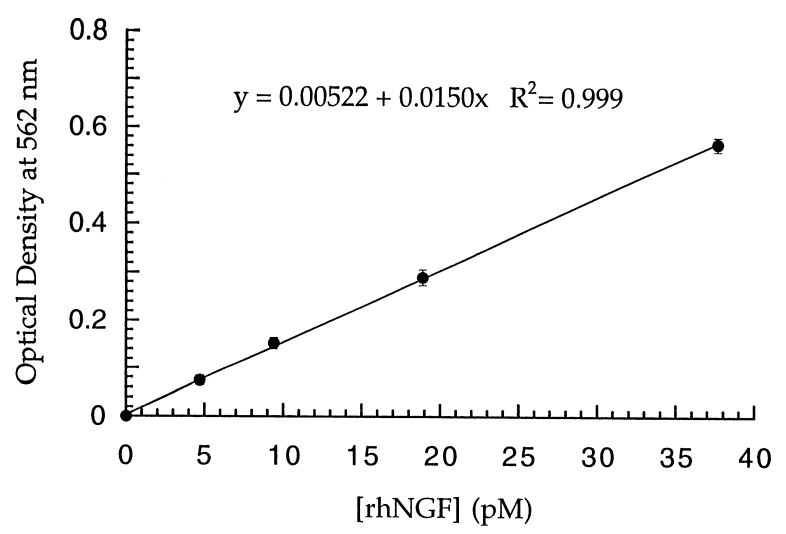

Fig. 1. A typical ELISA standard curve for rhNGF in the supernatant fraction from a brain tissue homogenate. Each point represents the mean \pm SEM $(n=4)$. The optical density found in the absence of added rhNGF has been subtracted from all data points. 
Possible Cross-Reactivity of BDNF and NT-3 in NGF ELISA. BDNF and NT-3 were tested using the ELISA to determine if they would cross-react with the anti-NGF monoclonal antibodies. We found that neither protein was detected in the assay, even at a 1000-fold higher concentration, indicating that the ELISA is specific for rhNGF, and no significant cross-reaction exists with other neurotrophins.

\section{In Vitro Stability of rhNGF}

As shown in Fig. 2, rhNGF was not significantly degraded by olfactory epithelium homogenates after $120 \mathrm{~min}$ incubation at $37^{\circ} \mathrm{C}$. Similarly, rhNGF was quite stable in the CSF over a $2 \mathrm{hr}$ period. However, in the presence of brain tissue homogenates, about $10 \%$ of added rhNGF was lost after $30 \mathrm{~min}$ incubation and about $30 \%$ was lost after $2 \mathrm{hr}$.

\section{Endogenous Levels of NGF in Various Brain Regions}

Endogenous NGF in the brain exhibited a region-specific distribution. Higher NGF levels were found in brain regions containing cholinergic neurons such as the septal nucleus $(180 \mathrm{pM})$ and in regions innervated by cholinergic neurons including hippocampus (230 pM) and olfactory bulb (200 pM). Other brain

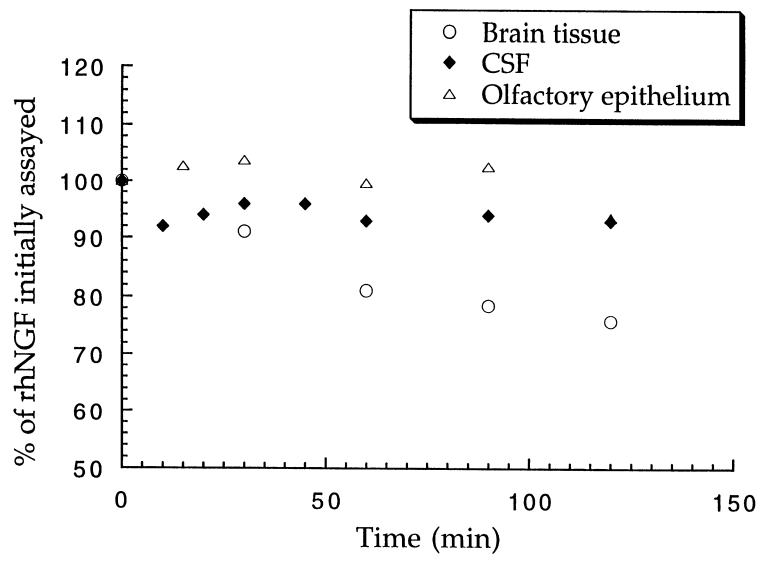

Fig. 2. The percentage of rhNGF remaining in CSF or in brain tissue or olfactory epithelium homogenates during $37^{\circ} \mathrm{C}$ incubation. regions such as the cerebellum and brain stem had lower levels of NGF, ranging from $50-70$ pM (Table 1).

\section{Time Course of rhNGF Uptake in the Olfactory Epithelium}

As shown in Fig. 3, following O.P. administration, high rhNGF levels were found in the olfactory epithelium up to $2 \mathrm{hr}$, decreasing rapidly with time thereafter. The rhNGF concentration of $4500 \mu \mathrm{M}$ at the time immediately after O.P. administration was decreased to $7 \mu \mathrm{M}$ at $20 \mathrm{hr}$.

Table 1

Endogenous NGF in different brain regions

\begin{tabular}{llll}
\hline Brain regions & {$[\mathrm{NGF}](\mathrm{pM})^{a}$} & $\begin{array}{l}\text { Brain } \\
\text { regions }\end{array}$ & {$[\mathrm{NGF}](\mathrm{pM})^{a}$} \\
\hline $\begin{array}{l}\text { Olfactory } \\
\text { Bulb }\end{array}$ & $200 \pm 17$ & $\mathrm{~B}^{b}$ & $160 \pm 16$ \\
$\begin{array}{l}\text { Hippocampus } \\
\text { 20 }\end{array}$ & $\mathrm{B}^{b}{ }^{b}$ & $130 \pm 11$ \\
$\begin{array}{l}\text { Septal } \\
\text { Nucleus }\end{array}$ & $180 \pm 18$ & $\mathrm{~B}^{b}$ & $140 \pm 19$ \\
Amygdala & $130 \pm 14$ & $\mathrm{~B}^{b}{ }^{b}$ & $160 \pm 14$ \\
Cerebellum & $70 \pm 9$ & Brain Stem & $50 \pm 12$ \\
\hline
\end{tabular}

${ }^{a}$ Mean \pm SEM, $n=3-7$.

${ }^{b} \mathrm{~B} 1-\mathrm{B} 4$ are four coronal sections of the cerebral hemisphere taken from anterior to posterior.

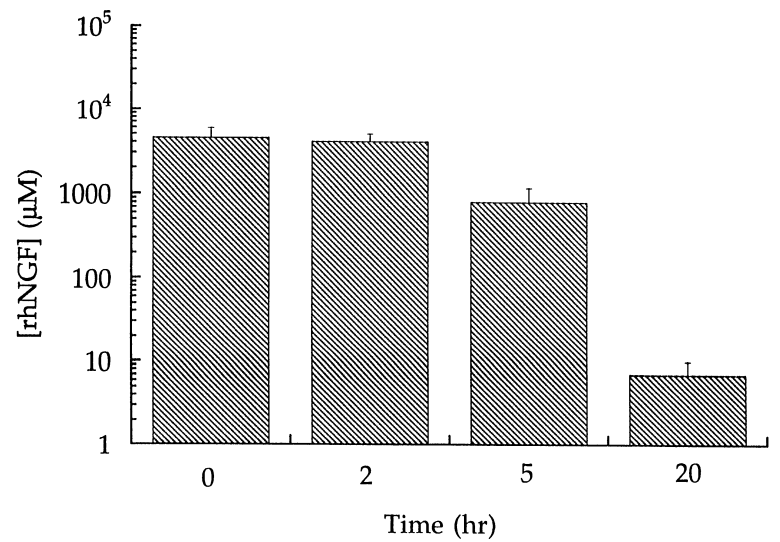

Fig. 3. Concentration of rhNGF (mean \pm SEM, $n=3-5$ ) in olfactory epithelium at $0,2,5$ and $20 \mathrm{hr}$ after the end of the O.P. administration. 


\section{Determination of rhNGF Concentrations Delivered to the Brain Following O.P. Administration}

Within $\quad 30-45 \quad \min$ following O.P. administration, a significant amount of rhNGF was delivered to the brain, achieving a concentration of $3400 \mathrm{pM}$ in the olfactory bulb and 660-2200 pM in adjacent brain regions. In addition, relatively high levels of rhNGF were found in some interior regions of the brain such as hippocampus $(240 \mathrm{pM})$ and amygdala (180 pM) (Table 2, note that these rhNGF concentrations were above the endogenous NGF levels). In contrast, significantly lower rhNGF was found in the brain following I.V. injection of the same dose (9.15 nmoles) and no detectable

Table 2

Concentration of delivered rhNGF in different brain regions following O.P. and I.V. administration

\begin{tabular}{|c|c|c|c|}
\hline Brain region & $\begin{array}{c}\text { O.P. }(\mathrm{pM}) \\
(9.15 \text { nmole) } \\
(\text { Mean } \pm \\
\text { SEM, } n=5)\end{array}$ & $\begin{array}{c}\text { I.V. (pM) } \\
(100 \text { pmole) } \\
\\
(\text { Mean } \pm \\
\text { SEM, } n=3)\end{array}$ & $\begin{array}{c}\text { I.V. (pM) } \\
\left(9.15 \text { nmole) }{ }^{a}\right. \\
(\text { Mean } \pm \\
\text { SEM, } n=6)\end{array}$ \\
\hline $\begin{array}{l}\text { Olfactory } \\
\text { bulb }\end{array}$ & $3400 \pm 1000$ & $\mathrm{ND}^{b}$ & $110 \pm 17^{c}$ \\
\hline B1 & $730 \pm 230$ & ND & $42 \pm 14^{c}$ \\
\hline B2 & $1300 \pm 620$ & ND & $75 \pm 17^{c}$ \\
\hline B3 & $660 \pm 240$ & ND & $65 \pm 19^{c}$ \\
\hline B4 & $740 \pm 300$ & ND & $60 \pm 15^{c}$ \\
\hline Cerebellum & $1800 \pm 1000$ & $3.8 \pm 5.0^{c}$ & $120 \pm 10^{c}$ \\
\hline Brain stem & $2200 \pm 1500$ & ND & $49 \pm 11^{c}$ \\
\hline Hippocampus & $240 \pm 50$ & $-{ }^{d}$ & $-{ }^{d}$ \\
\hline Amygdala & $180 \pm 40$ & $-{ }^{d}$ & $-{ }^{d}$ \\
\hline
\end{tabular}

\footnotetext{
${ }^{a}$ The endogenous levels were subtracted; all data represented rhNGF levels 30-45 min after O.P. administration. ${ }^{b}$ ND: not detectable. ${ }^{c} p<0.0005$. ${ }^{d}$ not available.
}

rhNGF reached the brain after I.V. administration of 100 pmoles.

\section{DISCUSSIONS}

ELISA is a sensitive and specific method for measuring both endogenous NGF and rhNGF delivered to the brain. The relatively low recovery of added rhNGF from the brain tissue could be due to tissue binding and enzymatic degradation. Although degradation may have been minimized by adding protease inhibitors in the assay, specific and non-specific tissue binding of rhNGF may contribute to its low recovery from the brain tissue. We therefore feel that it is important to correct for this loss by using standard curves prepared in supernatants obtained from brain tissue homogenates to which the rhNGF standards have been added.

While rhNGF was quite stable in the CSF and the olfactory epithelium in vitro, there was a significant loss of rhNGF when incubated in the presence of brain tissue homogenate. This is not surprising given the fact that the brain is known to contain many proteases which are released during homogenization. Delivery of rhNGF by the olfactory route, however, is not likely to expose the rhNGF to these intracellular proteases.

The endogenous levels of NGF in the brain determined in the present study were significantly higher than values previously reported in the literature $(14,34)$. In our study, we calculated endogenous NGF using a standard curve generated in the presence of brain tissue, whereas most of the previously reported data were calculated using standard curves obtained in buffer alone. We believe that standard curves in the presence of brain tissue, which correct for the tissue binding of NGF, should be used for the determination of endogenous NGF. In addition, multiple cycles of freeze-thawing were utilized in the present study to release NGF as much as possible from various binding sites in the brain.

Following O.P. administration, rhNGF was found to decrease with time in the olfactory epithelium. This decrease may not be due to enzymatic degradation since the in vitro study 
showed that rhNGF was fairly stable when incubated with olfactory epithelium. The olfactory epithelium probably serves as a depot for O.P.-delivered rhNGF from which rhNGF was further transported or distributed to the olfactory bulb and CSF. But it needs to be noted that most of the rhNGF may be lost from the olfactory epithelium due to turnover and ciliary clearance of the mucous layer and lymphatic drainage from the submucosa.

Within one hour following O.P. but not I.V. administration, significant concentrations of rhNGF were obtained in the olfactory bulb and, to a lesser extent, in other brain regions. Knusel et al. have reported that NGF concentration as low as $38 \mathrm{pM}$ is able to increase ChAT activity in septal cholinergic cell cultures (11). In the present study, as high as $3400 \mathrm{pM}$ of rhNGF has been found in the brain. This finding is very encouraging for its potential use for the treatment of AD. More importantly, after O.P. administration, rhNGF was not simply present on the surface of the brain, but indeed, relatively high levels of rhNGF were found in some interior brain regions including hippocampus and amygdala. Such regions are known to be severely affected in AD. The ability to deliver rhNGF to these areas of the brain by the olfactory pathway therefore has important therapeutic implications. Moreover, the distribution of rhNGF to interior brain areas as well as cerebellum and brain stem also suggests that some transport or distribution mechanisms other than diffusion may be involved in the movement of rhNGF to these areas, since simple diffusion of macromolecules in the brain parenchyma is very limited (20).

The detection of rhNGF by ELISA demonstrates that the rhNGF delivered to the brain is relatively intact. In our previous studies, although about $80 \%$ of the radiolabel found in the brain could be precipitated by trichloroacetic acid, we could not rule out the possibility that the radiolabel detected was from small radioactive fragments of the NGF molecule. In the present study, the rhNGF levels found in various brain regions assayed by ELISA were in good agreement with the NGF levels previously measured by radioactivity (6). These results provide evidence that most of the NGF delivered to the brain following O.P. administration remains relatively intact.

Two different transport mechanisms, i.e. intraand extraneuronal pathways, have been proposed for drug transport from the nasal cavity to the brain $(2,28,32)$. Intraneuronal transport involves the internalization of substances into the olfactory sensory neurons followed by axonal transport inside the neurons. This transport usually requires hours for substances to reach the olfactory bulb and days to reach other brain regions. For example, it has been found that following intranasal administration, wheat germ agglutinin-horseradish peroxidase (WGA-HRP, $62 \mathrm{kDa}$ ) is endocytosed and transported within olfactory neurons to the olfactory bulb where trans-synaptic transfer of the molecule occurs (28).

Alternatively, molecules may pass through patent intercellular clefts in the olfactory epithelium and diffuse along olfactory neurons to the subarachnoid space around the olfactory bulb $(2,32)$. Substances transported by this extraneuronal route reach the CSF and brain within $1-2 \mathrm{hr}(2)$. A variety of substances, including the antibiotic cephalexin (24), the steroid hormone progesterone (16), the peptides vasopressin (22) and cholecystokinin (23) and the protein horseradish peroxidase (HRP) (2), have all been proposed to undergo extraneuronal transport from the nasal cavity to the CNS. For instance, following unilateral intranasal administration, HRP (40 kDa) has been found within 45-90 min in intercellular openings of the olfactory epithelium as well as on the pial surface and nerve fiber layer of the olfactory bulb bilaterally in both rats and monkeys (2). Balin et al. have suggested that the rapid turnover of the olfactory sensory neurons, with the coexistence of mature and developing neurons in the olfactory epithelium, may explain the lack of tight junctions in some areas of the epithelium and the "leakiness" of the epithelium to intranasally administered HRP (2). This "leakiness" may even be more significant in $\mathrm{AD}$ patients with the degeneration of the olfactory 
epithelium. In more recent studies, direct transport of the peptides arginine-vasopressin and cholecystokinin- 8 from the nose to the brain has been reported in humans, providing encouraging evidence that use of drug delivery via the olfactory pathway may be possible in patients with a variety of brain disorders $(22,23)$.

Considering the rapid appearance of rhNGF in various brain regions and the lack of high-affinity NGF receptors on the surface of the olfactory epithelium, we hypothesized that NGF is most likely transported to the CSF and the brain via the extraneuronal route. This extraneuronal transport of macromolecules to the CSF was examined in a preliminary study using fluorescent-labeled dextran with a MW of $20 \mathrm{kDa}$ (FD20). We found that FD20 appeared in the CSF immediately after O.P. administration, reaching a peak concentration at about 15 min (data not shown). This result is consistent with findings previously reported by Sakane et al. (25) in which dextrans with molecular weights up to at least $20 \mathrm{kDa}$ were found to undergo transport from the nasal cavity to the CSF. It needs to be noted that a surgical procedure was conducted to cannulate the trachea and esophagus for intranasal administration in Sakane's study while nose drops were given without surgical procedures in our study. However, in our preliminary studies, only a trace amount of rhNGF was found in the CSF following O.P. administration of 45 nmoles rhNGF (not shown). The low level of rhNGF in the CSF may be a result of extensive binding to NGF receptors and other non-specific sites. Further studies are underway to elucidate the mechanism of rhNGF transport to the brain following olfactory pathway delivery.

In conclusion, the olfactory pathway appears to be a promising route for the delivery of potent drugs, including peptides and proteins, to the CNS. This method may be of particular benefit for the long-term treatment of Alzheimer's disease since it is less expensive, more convenient to use and less prone to systemic side effects than other methods currently in use.

\section{ACKNOWLEDGMENT}

This work was supported by the HealthPartners Foundation (St. Paul, MN), the Robert Wood Johnson Jr. 1962 Charitable Trust, the National Association of Retired Federal Employees, the Extendacare Foundation, the Alice M. O'Brien Foundation, a grant from Leroy F. Stutzman, and the Pharmaceutics Research Fund, Department of Pharmaceutics, College of Pharmacy, University of Minnesota. We thank Genentech, Inc. for generously providing rhNGF. We also thank Herb, Joel and Terrie for technical assistance and Robert Thorne for reviewing this manuscript.

\section{REFERENCES}

1. Baker H, Spencer RF, Transneuronal transport of peroxidase-conjugated wheat germ agglutinin (WGA-HRP) from the olfactory epithelium to the brain of the adult rat, Experimental Brain Research 63 (1986) 461-473.

2. Balin BJ, Broadwell RD, Salcman M, El-Kalliny M, Avenues for entry of peripherally administered protein to the central nervous system in mouse, rat, and squirrel monkey, Journal of Comparative Neurology 251 (1986) 260-280.

3. Bradbury MWB, Cserr HF, Drainage of cerebral interstitial fluid and of cerebrospinal fluid into lymphatics, in: Experimental Biology of the Lymphatic Circulation, Johnston MG (ed) (Elsevier Science Publishers, New York, 1985) 356-394.

4. Chou K-J, Donovan MD, Distribution of antihistamines into the CSF following intranasal delivery, Biopharmaceutics and Drug Disposition 18 (1997) 335-346.

5. De Lorenzo AJD, The olfactory neuron and the blood-brain barrier, in: Taste and Smell in Vertebrates, Wolstenholme GEW, and Knight J (eds) (Churchill and Co, London, 1970) 151-176.

6. Frey II WH, Liu J, Chen XQ, Thorne RG, Fawcett JR, Ala TA, Rahmam Y-E, Delivery of ${ }^{125}$ I-NGF to the brain via the olfactory route, Drug Delivery 4 (1997) 87-92. 
7. Gage FH, Bjorklund A, Stenevi U, Intrahippocampal septal grafts ameliorate learning impairments in aged rats, Science (1984) 533-536.

8. Hastings L, Evans JE, Olfactory primary neurons as a route of entry for toxic agents into the CNS, Neurotoxicology 12 (1991) 707-714.

9. Hefti F, Lapchak PA, Pharmacology of nerve growth factor in the brain, Advances in Pharmacology 24 (1993) 239-273.

10. Kida S, Pantazis A, Weller RO, CSF drains directly from the subarachnoid space into nasal lymphatics in the rat. Anatomy, histology and immunological significance, Neuropathology and Applied Neurobiology 19 (1993) 480-488.

11. Knusel B, Michel PP, Schwaber JS, Hefti F, Selective and nonselective stimulation of central cholinergic and dopaminergic development in vitro by nerve growth factor, basic fibroblast growth factor, epidermal growth factor, insulin and the insulin-like growth factors I and II, The Journal of Neuroscience 10 (1990) 558-570.

12. Kordower JH, Mufson EJ, Granholm A, Hoffer B, Friden PM, Delivery of trophic factors to the primate brain, Experimental Neurology 124 (1993) 21-30.

13. Kordower JH, Winn SR, Liu Y-T, Mufson EJ, Sladek Jr JR, Hammang JP, Baetge EE, Emerich $\mathrm{DF}$, The aged monkey basal forebrain: rescue and sprouting of axotomized basal forebrain neurons after grafts of encapsulated cells secreting human nerve growth factor, Proceedings of the National Academy of Sciences of the United States of America 91 (1994) 10898-10902.

14. Korsching S, Auburger G, Heumann R, Scott J, Phoenen $\mathrm{H}$, Levels of nerve growth factor and its mRNA in the central nervous system of the rat correlate with cholinergic innervation, The EMBO Journal 4 (1985) 1389-1393.

15. Kromer LF, Nerve growth factor treatment after brain injury prevents neuronal death, Science 235 (1987) 214-216.

16. Kumar TCA, David GF, Sankaranarayanan A, Puri V, Sundram KR, Pharmacokinetics of progesterone after its administration to ovariectomized rhesus monkeys by injection, infusion, or nasal spraying, Proceedings of the National Academy of Sciences of the United States of America 79 (1982) 4185-4189.

17. Lewis JL, Dahl AR, Olfactory mucosa: composition, enzymatic localization, and metabolism, in: Handbook of Olfaction and Gustation, Doty RL (ed) (M. Dekker, New York, 1995) 33-52.

18. Mobley WC, Rutkowski JL, Tennekoon GI, Buchanan K, Johnston MV, Choline acetyltransferase activity in striatum of neonatal rats increased by nerve growth factor, Science 229 (1985) 284-287.

19. Murphy C, Gilmore MM, Seery CS, Salmon DP, Lasker BR, Olfactory thresholds are associated with degree of dementia in Alzheimer's disease, Neurobiology of Aging 11 (1990) 465-469.

20. Pardridge WM, Transnasal and intraventricular delivery of drugs, in: Peptide Drug Delivery to the Brain, Pardridge WM (ed) (Raven Press, New York, 1991) 99-122.

21. Perlman S, Sun N, Barnett EM, Spread of MHVJHM from nasal cavity to white matter of spinal cord-transneuronal movement and involvemant of astrocytes, in: Corona- and Related Viruses, Talbot PJ, Levy GA (eds) (Plenum Press, New York, 1995) 73-78.

22. Pietrowsky R, Struben C, Molle M, Fehm HL, Born J, Brain potential changes after intranasal vs. intravenous administration of vasopressin: evidence for a direct nose-brain pathway for peptide effects in humans, Biological Psychiatry 39 (1996) 332-340.

23. Pietrowsky R, Thiemann A, Kern W, Fehm H, Born J, A nose-brain pathway for psychotropic peptides: evidence from a brain evoked potential study with cholecystokinin, Psychoneuroendocrinology 21 (1996) 559-572.

24. Sakane T, Akizuki M, Yoshida M, Yamashita S, Nadai T, Hashida M, Sezaki H, Transport of cephalexin to the cerebrospinal fluid directly from the nasal cavity, Journal of Pharmacy \& Pharmacology 43 (1991) 449-451.

25. Sakane T, Akizuki M, Taki Y, Yamashita S, Sezaki H, Nadai T, Direct drug transport from the rat nasal cavity to the cerebrospinal fluid: the relation to the molecular weight of drugs, Journal of Pharmacy \& Pharmacology 47 (1995) 379381.

26. Seiler M, Schwab M, Specific retrograde transport of nerve growth factor (NGF) from neocortex to nucleus basalis in the rat, Brain Research 300 (1984) 33-39.

27. Selkoe DJ, The molecular pathology of Alzheimer's disease, Neuron 6 (1991) 487-498. 
28. Shipley MT, Transport of molecules from nose to brain: transneuronal anterograde and retrograde labeling in the rat olfactory system by wheat germ agglutinin-horseradish peroxidase applied to the nasal epithelium, Brain Research Bulletin 15 (1985) 129-142.

29. Sutter A, Rippelle RJ, Harris-Warrick RM, Shooter EM, Nerve growth factor receptors, The Journal of Biological Chemistry 254 (1979) 5972-5982.

30. Suzuki N, Anterograde fluorescent labeling of olfactory receptor neurons by procion and lucifer dyes, Brain Research 311 (1984) 181-185.

31. Talamo BR, Rudel EA, Kosik KS, Lee VM-Y, Neff S, Adelman L, Kauer JS, Pathological changes in olfactory neurons in patients with Alzheimer's disease, Nature 337 (1989) 736-739.
32. Thorne RG, Emory CR, Ala TA, Frey II WH, Quantitative analysis of the olfactory pathway for drug delivery to the brain, Brain Research 692 (1995) 278-282.

33. Venero JL, Hefti F, Beck KD, Retrograde transport of nerve growth factor from hippocampus and amygdala to trkA messenger RNA expressing neurons in paraventricular and reuniens nuclei of the thalamus, Neuroscience 64 (1995) 855-860.

34. Whittemore SR, Ebendal T, Larkfors L, Olson L, Seiger A, Stromberg I, Persson H, Developmental and regional expression of $\beta$ nerve growth factor messenger RNA and protein in the rat central nervous system, Proceedings of the National Academy of Sciences of the United States of America 83 (1986) 817-821. 